\title{
China's wind-power potential
}

\author{
The nation can lead the world in wind energy - but its policies need to be more coherent.
}

$\Lambda$ quick glance at China's wind-energy statistics suggests that all the right things are happening. The country has doubled its capacity every year for the past three years; in 2007, it had surpassed a 5-gigawatt target three years ahead of schedule and, in 2008 , it hit a revised 10-gigawatt target two years early. Domestic manufacturers are positioned to produce more wind turbines than any other country over the next three years.

But the reality is much more complicated. Many wind projects do not even get off the ground because power companies cannot make enough money from them. Those that do go forward often produce turbines that simply sit, waiting for four months or more - a big delay in financial terms - to be hooked up to the electricity grid. And even when they are connected, they break down more often and are much less efficient at producing energy than those in many other countries (see page 372 ).

In May 2007, the Global Wind Energy Council, the Chinese Renewable Energy Industries Association, and the China Wind Energy Association released a joint memorandum proposing improvements in the industry. More than a year and a half later, the concerns expressed in the memorandum have been borne out and the recommendations remain just as pertinent.

For example, the bidding system used by the government to appoint developers favours companies that agree to supply electricity at cheaper prices - even if that price will render them unprofitable. As a result, many projects haven't even got started. International development companies with more experience and foreign turbinemakers with more efficient machines don't even bother to bid. The memorandum recommends setting 'feed-in tariffs', which offer a guaranteed rate for power supplied and offer developers more consistency and planning. China has moved in this direction, but the process of allocating the projects is still opaque and, from the perspective of developers and turbine-makers, frustrating.

The country also needs to significantly improve its grid, and to coordinate it with renewable-energy developments. Grid companies

are understandably not keen to embrace energy produced by wind an erratic and relatively expensive source - so it will take incentives to make the grid companies want to play ball.

Another way that China has discouraged foreign developers from entering the fray is by preventing companies with less than $51 \%$ Chinese ownership from taking advantage of the Clean Development Mechanism, which allows developed countries to offset their carbonreduction commitments under the Kyoto Protocol by investing in sustainable-energy projects in developing countries. If one has to be protectionist, surely it is better to do so in a way that bolsters domestic companies rather than simply penalizing foreign ones? Although some of China's policies have used this approach - it requires, for instance, that $70 \%$ of turbine parts be produced locally, encouraging foreign companies to build manufacturing facilities in China - it would do well to extend this across the board.

"China needs to significantly improve its grid, and to coordinate it with renewable-energy developments."

China could still learn a lot about turbine manufacturing and windfarm maintenance and management from countries that have much more experience in wind energy. One place to start would be to end its obsession with the number and capacity of its turbines and focus instead on producing power from them.

The speed with which the nation has scaled up to 10 gigawatts of wind energy is impressive. But if China could harness the 3,000 or so gigawatts of wind estimated to be available in the country, it would be able to cover almost all of its current electricity demand. That figure won't be achieved any time soon. But China should make good on plans to hit a more reasonable target - upping its 2020 projection from 30 gigawatts to 100 gigawatts. Operating at international standards of efficiency could produce $5 \%$ of the nation's energy needs and, depending on US policy over the next few years, make China the biggest producer of wind energy in the world. But only if China takes a more aggressive and rational approach will it make the most of its wind.

\section{Dismal no more}

\section{Europe's Joint Research Centre should be empowered to stimulate other EU institutions.}

7 he European Union is run by its council of ministers and its parliament, with the European Commission as its executive body. But there is another component that is generally unloved and yet has a crucial role: the Joint Research Centre (JRC). The seven large institutes that make up the JRC have remits that range from energy and environment to health and security. With a budget that approaches $€ 400$ million (US\$520 million) per year, the JRC is responsible for providing the scientific and technical support for EU policy. And according to a fairly positive evaluation released last week, led by David King, former science adviser to the British government, it now does this quite well.

The dismal reputation of the JRC originated in 1980s, after changing priorities in Europe had forced the centre to shift from its original mandate of researching nuclear energy, safety and security. It reinvented itself, and diversified its research fields, in a largely undirected and unmonitored way. Politicians soon started to complain about its lack of a clear mission and its inefficiency. In 1998, the institutes' labs were relaunched with a new, customer-orientated mission, tightly harnessing them to EU policy support and fulfilment.

The various JRC centres are now reasonably efficient machines, 